\title{
ENXERTO PERITONEAL AUTÓGENO E FIBROPLASIA: ESTUDO EXPERIMENTAL
}

\author{
PERITONEUMAUTOGENOUS GRAFT AND FIBROBLAST: AN EXPERIMENTAL \\ STUDY
}

\author{
Henrique Celso Silva, TCBC-MG ${ }^{1}$ \\ Alcino Lázaro da Silva, TCBC-MG ${ }^{2}$ \\ Célio Marcos de Oliveira ${ }^{3}$
}

\begin{abstract}
RESUMO: Objetivo: Avaliar se o enxerto autógeno de peritônio permanece vivo e que tipo de tecido conjuntivo predomina no local. Método: Foram utilizados 30 ratos machos para o enxerto de um fragmento de peritônio parietal do segmento ântero-superior do abdome, no interior do canal inguinal, fixado com monofilamento. Após 20 dias os animais foram sacrificados, a área doadora reparada e a área do enxerto foram retiradas para estudo histológico á microscopia óptica de luz. Em cinco animais a parede abdominal e o canal inguinal contralateral, sem enxerto, foram utilizados para o estudo de sua anatomia microscópica. Resultados: Houve um predomínio de fibroblastos (células jovens) no enxerto, em relação ao receptor e de colágeno denso não modelado em toda a área da intervenção, predominando no receptor, com índice de significância $p<0,01$. Conclusões: $O$ enxerto permanece vivo. O padrão histológico do tecido conjuntivo predominante no local é o tecido conjuntivo denso não modelado.
\end{abstract}

Descritores: Transplante autólogo; Cavidade peritoneal; Hérnia inguinal ; Fibroblastos.

\section{INTRODUÇÃO}

As descobertas das alterações no metabolismo dos colágenos fibrilares ${ }^{1-8}$, o melhor conhecimento da anatomia funcional e dos dismorfismos do canal inguinal, contribuíram para novas abordagens na correção das hérnias inguinais ${ }^{9-13}$. Sabemos que a fibroplasia induzida pela utilização de telas sintéticas como o polipropileno monofilamentar leva ao fechamento do defeito no assoalho do canal inguinal, reduz consideravelmente as recidivas a ponto de manter a correção mesmo em alguns casos em que a tela tenha que ser removida ${ }^{14}$, eleva o custo do procedimento, aumenta a morbidez devido a formação de seroma ${ }^{15}$, infecção, e como conseqüência têm desestimulado o seu uso por muitos cirurgiões. Como alternativa viável, no intuito de contornar estas situa- ções surgiram os auto-enxertos utilizando o saco herniário ${ }^{11,16-18}$. O estudo histológico mostrou ser este tecido constituído por uma camada interna de peritônio, uma camada externa fibrocolágena com feixes multidirecionais, vasos sangüíneos e fibras musculares lisas ${ }^{11-21}$. O aproveitamento deste material que é freqüentemente desprezado pelos cirurgiões tem a vantagem de não causar reação imunológica, não ter custos adicionais e não necessitar esterilização ${ }^{20}$. Os sacos das hérnias incisionais foram preliminarmente estudados e utilizados em nosso meio e tiveram o uso justificado por sua grossa espessura e riqueza de tecido fibroso ${ }^{22,23}$. A primeira tentativa de se utilizar transplante de tecido autógeno para correção do defeito herniário da região inguinal foi feita utilizando fáscia lata, não tendo sido relatado alteração estrutural na fáscia transplantada. Descreveu-se a reação

1. Cirurgião Geral, Hospital Nossa Senhora Auxiliadora Caratinga - MG.

2. Professor Titular de Cirurgia do Aparelho Digestivo da Faculdade de Medicina da UFMG.

3. Médico Patologista e Citopatologista do Laboratório Biocélula; Membro Titulado em Patologia pela SBP; Membro Titulado em Citopatologia pela SBC, Caratinga - MG.

Recebido em 23/09/2002

Aceito para publicação em 29/04/2003

Realizado No Serviço de Pós-Graduação em Cirurgia da UFMG (Universidade Federal de Minas Gerais) e Laboratório Biocélula. 
inflamatória aguda nessa intervenção e foi observado que esse tecido transplantado era invadido por fibroblastos do leito receptor e substituído por tecido fibroso $^{24}$. Complicações na área doadora do enxerto levaram ao abandono do método. Posteriormente foi usada a cútis sem a epiderme como reforço de ligamentos e tecidos enfraquecidos, e mais tarde introduzido o uso de pele total ${ }^{25}$. Esses auto-enxertos promovem uma metaplasia fibrosa no local e o desestímulo à continuidade do seu uso foi devido aos relatos de formação de cisto de retenção epidérmico ${ }^{26}$. Em estudos experimentais o peritônio parietal foi utilizado como enxerto autógeno para reforço em suturas de cólon ${ }^{27}$. Fixados sob pressão com clamps após ter suas interfaces borrifadas com solução de plasma e trombina, foi constatado que adere ao local firmemente. Repetido o experimento com fixação do enxerto, sobre a sutura intestinal, com fio de algodão não houve comprovação da eficácia do método em prevenir vazamento da sutura, quando comparado ao grupo controle, mas o estudo microscópico da área enxertada evidenciou a formação de tecido de granulação entre as interfaces com direcionamento dos fibroblastos da parede intestinal para o enxerto e deposição de colágeno $^{28}$. Outros experimentos com auto-enxerto de peritônio, utilizado como selo, para fechamento de perfurações em vários segmentos do tubo digestivo ${ }^{29}$, descreveram a formação de fibrose próxima ao fio de fixação do enxerto. O experimento em cães, com auto-enxerto de peritônio para lâmina externa da bainha do reto, mostrou transformação em uma cicatriz fibrosa com reforço do local e desaparecimento do mesótelio ${ }^{17}$. Sendo a camada interna do saco herniário constituída de peritônio, é nosso objetivo verificar através da histologia, se o auto-enxerto de peritônio parietal fixado no canal inguinal, mantêm-se vivo, que modificações ocorrem e que tipo de tecido conectivo é formado no local. Para atender a estes objetivos foram feitos estudos quantitativos dos fibroblastos (células jovens), fibrócitos (células maduras) e das variações morfológicas da matriz extracelular representadas pelo colágeno denso e frouxo.

\section{MÉTODO}

No período de 30 de junho de 2001 a 30 de dezembro de 2001, foi realizado o experimento em 30 ratos $^{30}$ machos da raça Wistar, variação de peso entre $150 \mathrm{~g}$ e $200 \mathrm{~g}$ idade média quatro meses.Auxiliado por uma Veterinária utilizou-se como indutor anesté- sico algodão umedecido em éter comercial e para manutenção, cloridrato de ketamina intramuscular, na dose de $40 \mathrm{mg} / \mathrm{kg}$ de peso. Retirado um fragmento de $1,5 \mathrm{~cm} \times 1 \mathrm{~cm}$ do peritônio parietal, posterior ao músculo reto do abdome e colocado em solução fisiológica para não ressecar, foi realizada síntese da cavidade com um único ponto de monofilamento 5.0 na lâmina anterior da bainha do músculo reto sem sutura do peritônio. Utilizou-se o mesmo fio para a síntese da pele. Posteriormente o canal inguinal foi aberto e fixou-se o fragmento de peritônio retirado do abdome à parede lateral posterior deste com dois pontos de monofilamento diametralmente opostos nas extremidades do fragmento, sem tensão, com sua face cruenta voltada para parede onde foi fixado. A síntese das fascias que envolvem o cordão espermático e da pele que o recobre foram realizadas com a mesma técnica acima descrita. Depois de 20 dias os animais foram mortos, a pele do local operado foi removida, a parede abdominal e o canal inguinal da área da intervenção prévia foram retirados para estudo histopatológico. Posteriormente esse material foi fixado em formol a $10 \%$. Foram feitos os mesmos procedimentos na área contralateral íntegra em cinco ratos. Após o processamento das amostras, foram incluídas em parafina histológica e confeccionadas lâminas com cortes de cinco micra para estudo. As técnicas de coloração empregada foram a Hematoxilina-Eosina e o Tricrômico de Gomori. Todas as lâminas foram examinadas por um observador único, médico patologista e acompanhado pelos autores do trabalho. De cada bloco de parafina foram confeccionadas duas lâminas e dependendo da perfeição dos cortes necessitou-se novas lâminas. Numa primeira etapa as estruturas habituais da parede abdominal e do canal inguinal como: peritônio, tecido fibroadiposo e musculatura estriada esquelética foram estudados com detalhes. Numa segunda etapa utilizando o método da Hematoxilina-Eosina (HE), analisou-se a área doadora, após 20 dias da retirada do fragmento para enxerto, sobre o aspecto de reparação tecidual. No sítio do enxerto observou-se a fixação do fragmento transplantado entre os orifícios do monofilamento e analisou-se a fibroplasia. A coloração Tricômica de Gomori foi empregada em algumas lâminas para melhor observação do tecido colágeno que se corava em tom esverdeado. Para análise dos dados foram comparadas as áreas do enxerto e do leito receptor. A identificação do tecido enxertado foi possível em 23 ratos e em sete não con- 
Tabela 1 - Número de lâminas do enxerto que preencheram 100\% do campo visual microscópico, com cada elemento do estudo.

Enxerto Normatizado

\begin{tabular}{ccccc}
\hline $\begin{array}{c}\text { Campo Visual } \\
(\%)\end{array}$ & $\begin{array}{c}\text { Fibroblastos } \\
\text { Jovens }\end{array}$ & $\begin{array}{c}\text { Fibroblastos } \\
\text { Maduros }\end{array}$ & $\begin{array}{c}\text { Colágeno } \\
\text { Fouxo }\end{array}$ & $\begin{array}{c}\text { Colágeno } \\
\text { Denso }\end{array}$ \\
\hline 100 & 6,4 & 18,3 & 10,05 & 13,95 \\
\hline
\end{tabular}

seguimos separar o que era tecido enxertado do tecido receptor. Para fins estatísticos foram quantificados apenas como área receptora. $\mathrm{O}$ estudo quantitativo de fibroblastos, fibrócitos, colágeno denso, colágeno frouxo foi realizado separadamente e criou-se um esquema simples de porcentagem, baseado no campo visual microscópico com a objetiva X10 empregando uma escala a ser preenchida por cada elemento que variou de $10 \%$ a $100 \%$ do campo visual. Dividimos as lâminas em três grupos de 10 e cada grupo foi quantificado seqüencialmente sem interrupção por um único observador. Para efeito de comparação estatística agrupamos as lâminas com cada elemento de estudo, de forma que um determinado número de ratos teria um número $\mathrm{X}$ de lâminas com $100 \%$ do campo visual microscópico preenchido por cada um desses elementos. Procuramos também caracterizar o tipo do colágeno denso formado. O estudo foi realizado em microscópio de luz trinocular, marca ZEISS com ocular $\mathrm{x} 10$ e objetivas $\mathrm{x} 4, \mathrm{x} 10$, $\mathrm{x} 20 \mathrm{e} \times 40$. Foram captadas fotomicrografias em computador por equipamento "Sansung" conectado à ocular do microscópio e impressas por impressora Epson Stylus Collor 740. Utilizou-se o teste Qui-quadrado $\left(\mathrm{X}^{2}\right)$ para avaliar a diferença quantitativa entre o colágeno frouxo e denso, fibroplastos e fibrócitos no tecido enxertado e no leito receptor. Encontrouse, $\mathrm{p}<0,01$.

\section{RESULTADOS}

As tabelas 1 e 2 mostram, após normatização, o número de lâminas do enxerto e do receptor que preencheram $100 \%$ do campo visual microscópico com cada componente do tecido de sustentação estudado.

No tecido enxertado 6,4 lâminas tiveram $100 \%$ do campo visual preenchida por fibroblastos correspondendo a 27,82\%; 18,3 lâminas de fibrócitos 44,22\%; 10,05 lâminas de colágeno frouxo 43,69\%; 13,95 lâminas de colágeno denso não modelado $60,65 \%$. No leito receptor 0,8 lâmina teve $100 \%$ do campo visual preenchida por fibroblastos 2,66\% ; 26,7 lâminas com fibrócitos 79,56\%; 2,4 lâminas com colágeno frouxo $8 \%$; 26,8 lâminas com colágeno denso não modelado 89,33\%.

Constatou-se intensa fibroplasia e regeneração do mesotélio na reparação tecidual da área doadora do enxerto em $100 \%$ das lâminas (Fotomicrografia 1). Constatou-se reação inflamatória crônica em torno do monofilamento em $100 \%$ dos casos (Fotomicrografia 2). O mesótelio desapareceu em $100 \%$ das lâminas no tecido enxertado (Fotomicrografia 3).

Notou-se intensa formação de tecido colágeno denso não modelado na área receptora, 89,33\% (Fotomicrografia 4). Orifícios do fio de fixação do enxerto ao leito receptor são vistos na Fotomicrografia 5.

Tabela 2 - Numero de Lâminas do receptor que preencheram $100 \%$ do campo visual microscópico, com cada elemento do estudo.

Receptor Normatizado

\begin{tabular}{ccccc}
\hline $\begin{array}{c}\text { Campo Visual } \\
(\boldsymbol{\%})\end{array}$ & $\begin{array}{c}\text { Fibroblastos } \\
\text { Jovens }\end{array}$ & $\begin{array}{c}\text { Fibroblastos } \\
\text { Maduros }\end{array}$ & $\begin{array}{c}\text { Colágeno } \\
\text { Fouxo }\end{array}$ & $\begin{array}{c}\text { Colágeno } \\
\text { Denso }\end{array}$ \\
\hline 100 & 0,8 & 26,7 & 2,4 & 26,8 \\
\hline
\end{tabular}




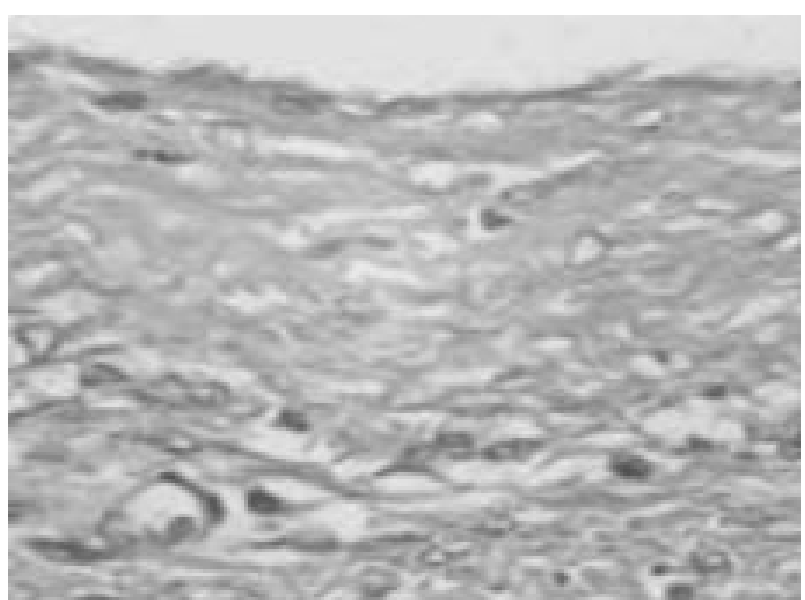

Figura 1 - Peritônio da área doadora evidenciando regeneração mesotelial e transformação do tecido conjuntivo frouxo em tecido conjuntivo denso modelado. (HE X 20).

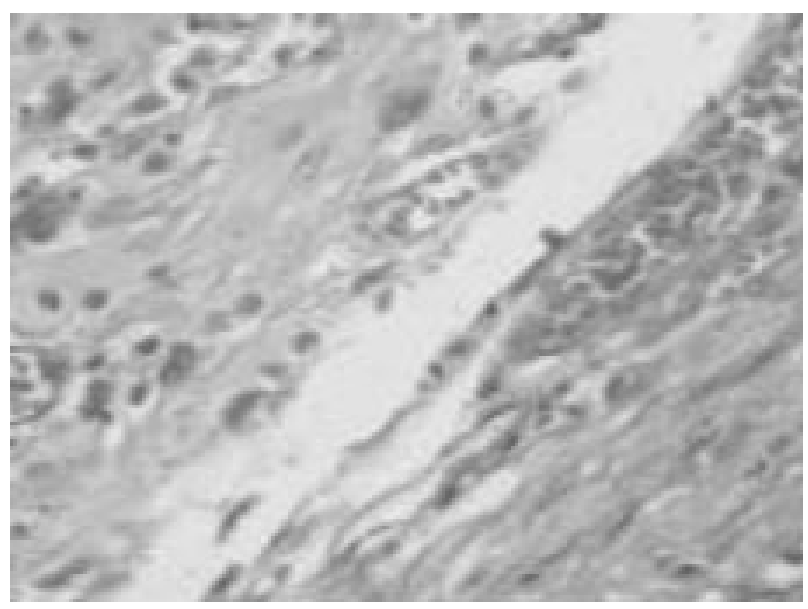

Figura 3 - Desaparecimento do mesotélio no tecido enxertado. $H E(x 20)$.

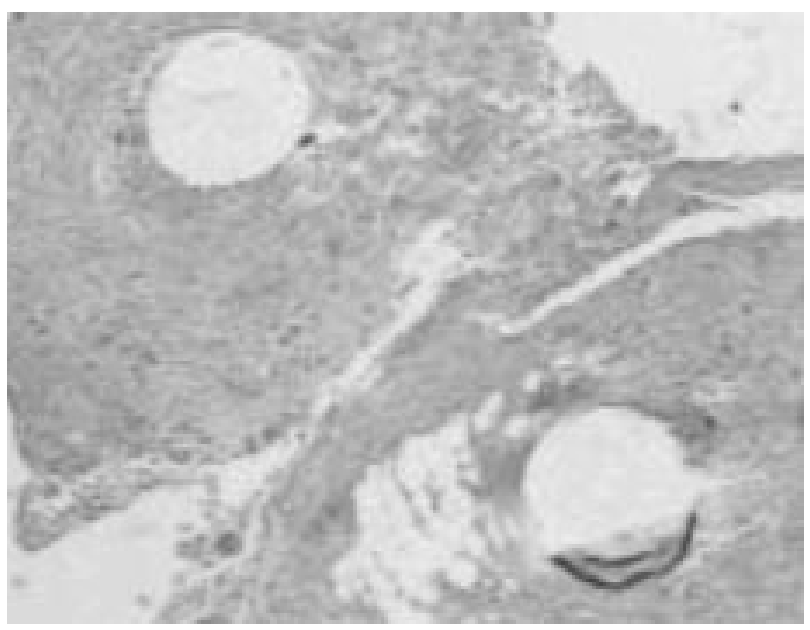

Figura 5 - Auto-enxerto de peritônio mostrando orifícios do monofilamento de fixação. $H E(x 10)$.

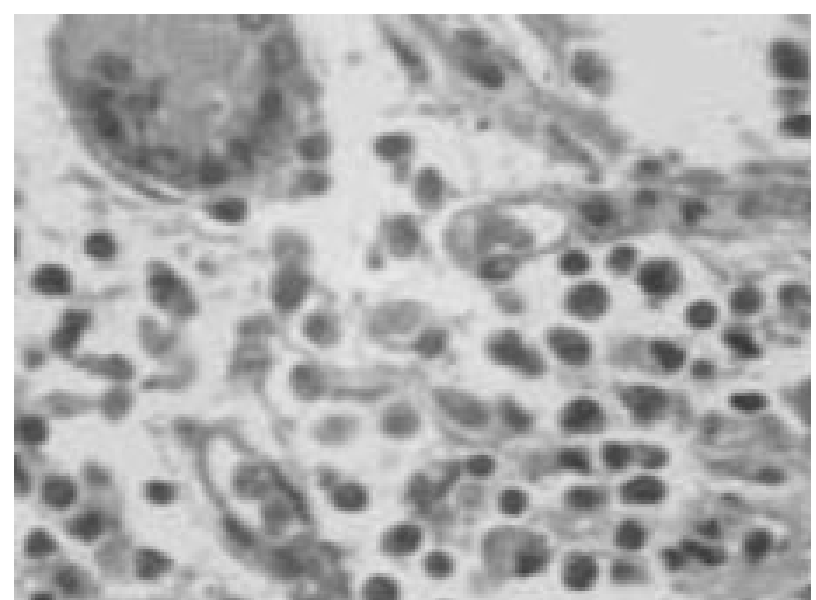

Figura 2 - Reação granulomatosa tipo corpo estranho,em torno do monofilameto, seta maior, Fibroblastos, neoformação vascular, células mononucleadas, setas menores. HE (x40).

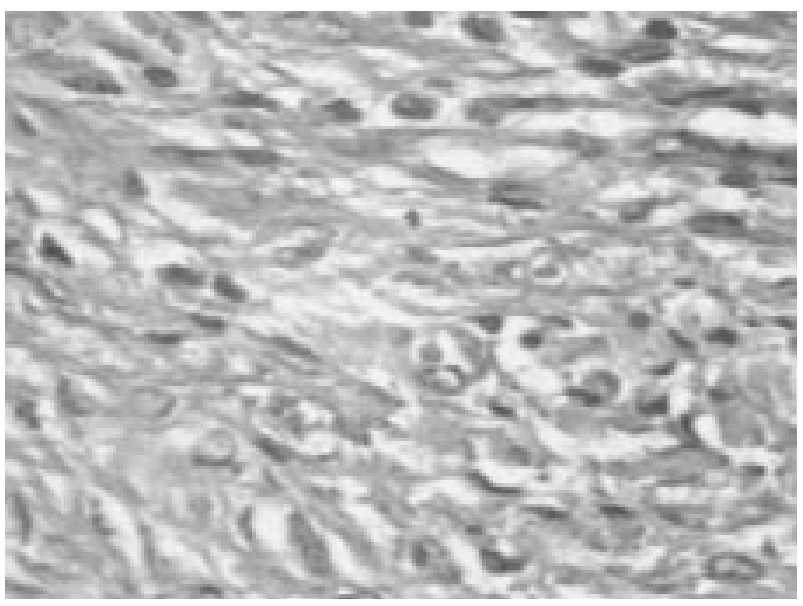

Figura 4 - Fotomicrografia da área receptora mostrando fibroplasia com formação de tecido colágeno denso não modelado,setas menores, e neovascularização, seta maior. HE(x40).

\section{DISCUSSÃO}

Em nossas observações uma intensa fibroplasia foi demonstrada no local 20 dias após o auto-enxerto peritoneal. Houve um predomínio de tecido conjuntivo denso não modelado representado, principalmente, pelo conteúdo de colágeno denso que preencheu $89,33 \%$ das lâminas da área receptora e $60,65 \%$ das lâminas da área do enxerto. As células predominantes foram os fibrócitos (fibroblastos maduros). Esse estudo reveste-se de importância ao atentarmos para o fato de que a fibroplasia induzida pelos materiais sintéticos é a responsável pelo reforço desejado na correção das hérnias. Como alternativa de seu uso estudos propõem a utilização de tecidos autógenos $^{31,32}$ para induzir a produção normal de 
colágenos. De acordo com a literatura consultada nos auto-enxertos de fáscia lata e saco herniário respectivamente, ocorre uma invasão de fibroblastos do leito receptor para o enxerto ${ }^{16,24}$. Pela avaliação de nossas lâminas concordamos com essas afirmações uma vez que os fibrócitos são as células predominantes tanto na área receptora como no enxerto propriamente dito. Mas constatamos que o tecido enxertado contém fibroblastos jovens em 27,82\% das lâminas contra somente $2,66 \%$ das lâminas da área receptora contendo essas mesmas células. Esse achado nos leva a inferir que o tecido enxertado, em uma fase posterior à infiltração de fibroblastos do leito receptor, seguido pela neovascularização, passou a produzir células jovens, fato que caracteriza a nosso ver a permanência da vitalidade do tecido enxertado e que os fibroblastos nos auto-enxertos não são mera infiltração dos tecidos vizinhos como descrita na literatura pesquisada. Há, portanto uma participação ativa do tecido transplantado na produção da fibroplasia. Apesar da neovascularização presente em $100 \%$ das lâminas não nos baseamos nela como sinal de integração do enxerto pelo fato da mesma apresentar-se em toda infiltração de fibroblastos e de que a simples reação inflamatória em torno do monofilamento utilizado para fixação do enxerto, poderia provocá-la.

Assim como Souza Filho ${ }^{17}$, Shafei e Azzam $^{16}$, no presente trabalho, também observa- mos que o mesotélio desapareceu no tecido enxertado em 100\% das lâminas. Souza Filho justificou o fato com base em dados da literatura que descreve a multipotencialidade da célula mesotelial que lhe confere a capacidade de se transformar em fibroblastos. Quando comparamos as lâminas da área doadora do enxerto, após reparação tecidual, com as lâminas do local do auto-enxerto no canal inguinal, decorrido o mesmo período de tempo, vimos que o mesotélio se refez integralmente somente na área doadora e que seu tecido conjuntivo frouxo subjacente transformou-se em tecido conjuntivo denso modelado. Com base na explicação anterior questionamos o porque do mesotélio do enxerto se transformar em fibroblasto e se recompor integralmente na reparação tecidual da área doadora. De acordo com a literatura pesquisada ${ }^{33-35}$ as reparações teciduais se comportam de formas diferentes conforme o grau de lesão das células do tecido de sustentação e desta forma podemos postular que no tecido enxertado ocorre morte das células especializadas com perda da arquitetura do tecido de sustentação (principalmente a membrana basal) e a reparação se faz através da proliferação das células não especializadas desse tecido, resultando numa cicatriz fibrosa. Concluimos que o enxerto permanece vivo. O padrão histológico do tecido conjuntivo predominante no local é o tecido conjuntivo denso não modelado.

\begin{abstract}
Background: The authors performed a histological investigation of the inguinal canal region which had received an autogenous graft of parietal peritoneum to evaluate if the graft remains alive and what type of conjunctive tissue prevails on the site. Method: Thirty male rats received grafts, obtained from a fragment of parietal peritoneum of the anterosuperior segment of the abdomen, into their inguinal canals, which were fixed with monofilaments stiches. Twenty days later the animals were killed, the donor area repaired and the graft area was submited to histological survey through optic light microscopy. In five animals the abdominal wall and the counter lateral inguinal canal without graft were used to surveillance of their microscopy anatomy. Results: There has been a predominance of fibroblast (young cells) on the graft in relation to the receiver and of the thick unshaped collagen in the intervention area, with a predominance on the receiver with a $p<0,01$ significance index. Conclusions: The graft stays alive. The histological pattern of the local prevailling conjuctive tissue is the thick unshaped conjuctive tissue.
\end{abstract}

Key Words: Transplantation, autologous; Peritoneal cavity; Inguinal hernia; Fibroblasts. 


\section{REFERÊNCIAS}

1. Bellón JM Buján J, Honduvilla NG, et al. - Study of biochemical substrate and role of metalloproteinases in fascia transversalis from hernial processes. Eur $\mathbf{J}$ Clin Invest, 1997, 27(6):510 -516.

2. Fleischmajer R, Perlish JS, Burgeson RE, et al. - Type I and type III collagen interactions during fibrillogenesis. Ann N Y Acad Sci, 1990, 580:161-175.

3. Friedman DW, Boyd CD, Norton P, et al. - Increases in type III collagen gene expression and protein synthesis in patients with inguinal hernias. Ann Surg, 1993, 218(6):754-760.

4. Klinge U, Zheng H, Si ZY, et al. - Synthesis of type I and III collagen, expression of fibronectin and matrix metalloproteinases-1 and -13 in hernial sac of patients with inguinal hernia. Int J Surg Investig, 1999, 1(3):21927.

5. La Bourene JI, Coles JG, Johnson DJ, et al. - Alterations in elastin and collagen related to the mechanism of progressive pulmonary venous obstruction in a piglet model. A hemodynamic, ultrastructural and biochemical study. Circ Res, 1990,66 (2):438-456.

6. Lapiere M, Nusgens B, Pierard GE - Interaction between collagen type I and type III in conditioning bundles organization. Connect Tissue Res, 1977, 5(1):21-29.

7. Pans A, Albert A, Lapiere CM, et al. - Biochemical study of collagen in adult groin hernias J Surg Res, 2001,95(2):107-113.

8. Henkel W, Glanville RW - Covalent crosslinking between molecules of type I and type III collagen. The involvement of the $\mathrm{N}$-terminal, nonhelical regions of the alpha 1(I) and alpha 1(III) chains in the formation of intermolecular crosslinks. Eur J Biochem, 1982,122(1):205-213.

9. Abrahamson J - Etiology and pathophysiology of primary and recurrent groin hernia formation. Surg Clin North Am, 1998, 78(6):953-972.

10. Falci F- Hernioplastia incisional com prótese metálica. Rev Col Bras Cir, 1969, 1(5): 33-44.

11. Lázaro da Silva A - O uso do saco herniário no reforço da hernioplastia inguinal. Rev Col Bras Cir, 1995, 22(3):153-154.

12. Lichtenstein IL, Shulman AG - Ambulatory outpatient hernia Surgery. Including a new concept, introducing tension-free repair. Int Surg, 1986, 71(1):1-4.

13. Lima JM - Tratamento cirúrgico das hérnias inguinais recidivadas: modificação da técnica de Mc Vay pelo uso da malha de polipropileno monofilamentar. Rev Col Bras Cir, 2000, 27(1):27-31.

14. Falci $\mathrm{F}$ - "Análise Crítica das Próteses na Região Inguinal”. In Lázaro da Silva A (ed) - Hérnias da Parede Abdominal. Clínica Brasileira de Cirurgia. Rio de Janeiro. Atheneu, 1997, pp.141-151.
15. Barone CA - Tratamento cirúrgico das hérnias da parede abdominal com prótese de Marlex. Rev Col Bras Cir, 1970,5(13):300-311.

16. Shafey OA, Azzam ZA - Hernioplasty using the hernial sac in repair of inguinal hernia. Am Surg, 1976, 42(4):268-272.

17. Souza Filho ZA - Auto-enxerto peritoneal no tratamento cirúrgico da parede abdominal. Dissertação (concurso à Livre-Docência da disciplina de técnica operatória - Bases da cirurgia). Curitiba. Universidade Federal Paraná, 1974, $57 \mathrm{p}$.

18. Orsi FL, Marinho EB,Lougon LA, et al. - Reforço da parede posterior nas hérnias inguinais com o próprio saco herniário. Rev Col Bras Cir, 1995,(2): 22- 151.

19. Barbosa CA, Lázaro da Silva A - Saco herniário. In Lázaro da Silva A. (ed) - Hérnias da Parede Abdominal. Clinica Brasileira de Cirurgia. Rio de Janeiro. Atheneu, 1997, pp 131-139.

20. Lúcio SP - Emprego do saco herniário, no reforço parietal nas hérnias inguinais indiretas do adulto. Dissertação (Doutorado em cirurgia abdominal). Belo Horizonte. Universidade Federal de Minas Gerais, 1997, 122p.

21. Faria LP - Estudo histológico e imuno - histoquímico do saco hermiário de hérnias inguinais indiretas no homem. Dissertação (Doutorado em cirurgia abdominal). Belo Horizonte. Universidade Federal de Minas Gerais, 2000, 67p.

22. Lázaro da Silva A - Plástica com o saco hermiário na correção das hérnias incisionais. Hospital, 1971, 79(2):129-134.

23. Escalante JR, Diogo Filho A, Andrade JI, et al. - Tratamento de hérnias incisionais volumosas pela técnica de Lázaro da Silva. Rev Col Bras Cir, 1983, 10(1):24-28.

24. Couto RC - Transplante de derme, gordura fascia, cartilagem e osso. In Sucena RC (ed) - Cirurgia Plástica. São Paulo, Roca, 1981, pp. 69-88.

25. Mair GB - Preliminary report on the use of whole skingraft a substitute for fascial sutures in the treatment of hernial. Br J Surg, 1945, 32:381-385.

26. Clarke $\mathrm{SH}-\mathrm{The}$ formation of inclusion dermoid cysts following Whole thickness Skin graft repair of hernia. Br J Surg, 1952, 39:346-349.

27. Devine $\mathbf{J}$ - Preliminary report of a method for the prevention of leakage of intestinal anastomosis. An experimental study. Surg Gynecol Obstet, 1946, 82:475479.

28. Chester ST, Bell HG, Mccorkle HJ - The use of free peritoneal grafts in intestinal anastomosis. Surg Gynecol Obstet, 1949, 89:605-608.

29. Moore RM, Singleton AO - Value of free grafts of peritoneum or pleura in sealing large defects in the alomentary tract of the dog. Surg Gynecol Obstet, 1951, 92:466-468. 
30. Petroianu A - Aspectos éticos na pesquisa em animais. Acta Cir Bras,1996, 11(3): 157-164.

31. Oughterson AW - The hypertrophy of fascia and, its uses in the repair of large scrotal herniase. Surg Gynecol Obstet, 1929, 49:387-391.

32. Poth EJ - Inguinal hernia repair using the rectus pyramidalis sheath. Am J Surg, 1971, 122(5):699-702.

33. Stevens A, Lowe J - Histologia Humana. $1^{\text {a }}$ Edição. Manole, 2001.

34. Montenegro MR, Franco M (eds) - "Patologia. Pro-

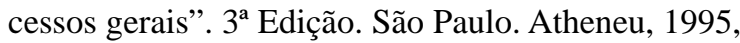
$282 \mathrm{p}$.
35. Junqueira LC, Carneiro J - "Tecido conjuntivo". In Junqueira LC, Carneiro J - Histologia básica - texto e atlas. $7^{\mathrm{a}}$ Edição. Rio de Janeiro. Guanabara Koogan, 1990, pp. 65-87.

Henrique Celso Silva

Rua Coronel Antônio Salim, 310

Centro

35300-010 - Caratinga-MG

Tel.: (33) 3321-8865 / (33) 3321-2743 